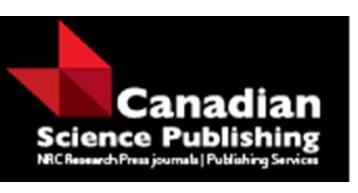

Canadian Journal of Physics

Revue canadienne de physique

\title{
Effect of co-doping on dielectric function spectra and static refractive indices of singlewalled carbon nanotubes: A first principles study
}

\begin{tabular}{|c|c|}
\hline Journal: & Canadian Journal of Physics \\
\hline Manuscript ID & cjp-2016-0823.R1 \\
\hline Manuscript Type: & Article \\
\hline Date Submitted by the Author: & 15-Mar-2017 \\
\hline Complete List of Authors: & $\begin{array}{l}\text { sharma, deepa; SUS Government Post-graduate College, Matak- } \\
\text { Majri(Haryana) India, Department of Physics; National Institute of } \\
\text { Technology, Department of Physics } \\
\text { jaggi, neena; National Institute of Technology, Physics }\end{array}$ \\
\hline Keyword: & $\begin{array}{l}\text { single-walled carbon nanotubes, co-doping, optical properties, density } \\
\text { functional theory, CASTEP }\end{array}$ \\
\hline $\begin{array}{r}\text { Is the invited manuscript for } \\
\text { consideration in a Special } \\
\text { Issue? : }\end{array}$ & N/A \\
\hline
\end{tabular}

\section{SCHOLARONE ${ }^{m}$ \\ Manuscripts}




\title{
Effect of co-doping on dielectric function spectra and static refractive indices of singlewalled carbon nanotubes: A first principles study
}

\author{
Deepa Sharma ${ }^{1^{*}}$, Neena Jaggi ${ }^{2}$ \\ SUS Govt. College, Matak-Majri, Haryana (India) ${ }^{1}$ \\ National Institute of Technology, Kurukshetra, Haryana (India) ${ }^{1,2}$ \\ E-mail: bhargava.dp@gmail.com; neena jaggi@rediffmail.com
}

\begin{abstract}
:
This paper details a density functional theory (DFT) based ab initio study on the effect of co-doping on the dielectric function spectra and refractive indices of single-walled carbon nanotubes (SWCNTs). Dielectric function spectra of a pristine $(8,0)$ SWCNT , $(8,0)$ SWCNT co-doped with Aluminum (Al) \& Phosphorus $(\mathrm{P}),(8,0)$ SWCNT co-doped with Al, P and Nitrogen $(\mathrm{N}),(9,0)$ SWCNT doped with Al and $(9,0)$ SWCNT co-doped with Al \& Boron (B) have been calculated using DFT based Cambridge sequential total energy package (CASTEP) code. Polarized and unpolarized light as well as light through polycrystalline media have been considered. Analysis involves calculation and comparison of static refractive indices of the pristine and co-doped SWCNTs. Co-doping with $\mathrm{Al}$ and $\mathrm{P}$ results in a substantial increase in the value of the static refractive index while co-doping of $\mathrm{Al}, \mathrm{N}$ and $\mathrm{P}$ results in a reduction in the value of static refractive index though it does not fall lower than that of the pristine SWCNT. Thus, it can be concluded that co-doping with atoms of different combinations of elements can be evolved as a novel and effective tool for tuning the dielectric function and static refractive
\end{abstract}


index values of SWCNTs. It will prove to be highly significant for effective designing of various sensitive optical devices using SWCNTs.

Keywords: single-walled carbon nanotubes, co-doping, optical properties, density functional theory, CASTEP, material studio

\section{Introduction}

Singlewalled Carbon nanotubes (SWCNTs) are recognized as one of the most promising candidates to be used in future electronic devices for their superior physicochemical properties [1-3]. These molecular wires have been successfully integrated into a variety of device applications [4-14]. The effect of defects on their photo-physical and photo-chemical properties [15], exciton-phonon interactions [16], biexciton formation [17, 18], exciton-plasmon coupling [19], external magnetic [20] and electric fields $[19,21]$ is being extensively studied. CNTs have also seeked attention of many researchers working on projects related to solar cells and solar energy methods [22-30]. The extraordinary properties of CNTs, such as their light weight, excellent mechanical strength, three-dimensional flexibility and outstanding electro-catalytic properties can be used to improve the performance of solar cells. In addition, SWCNTs are also being incorporated in optical systems as anti-reflection coatings (ARCs). These transparent surface coatings with suitable optical path differences can suppress the reflection of substrates. In addition to these excellent optical properties, these SWCNT ARCs also exhibit self-cleaning ability because of the high fraction of air trapped between arrays [29, 30]. Hybrid carbon nanotube systems - nanotubes containing extrinsic atomic type species such as semiconductor quantum dots, extrinsic atoms or ions, are shown to be promising candidates to extend the potential of CNTs for the development of new nano-optoelectronic devices with customized 
properties - both application oriented ( e.g. photovoltaic devices of improved light-harvesting efficiency) [9] and for fundamental research (nanophotonics, nanoplasmonics, and quantum information processing)[31,32]. Such doping has already been achieved by a variety of techniques, including arc discharge [33], pyrolysis [34] and chemical vapor deposition [35]. Their strong potential for the future generation of the optoelectronic device applications, however, lies in the ability to tune their physical properties in a controllable, predictable way [36]. It is well known that the introduction of donor/acceptor levels through substitutional doping in a material is an attractive alternative for controlling the electronic properties and conductivities of nanotubes. $\mathrm{B}$ and $\mathrm{N}$ being the closest to $\mathrm{C}$ in the periodic table are no doubt the obvious choice when it comes to doping. That is why B, N doping \& B-N co-doping has already been extensively studied and exploited [37-39].. Many researchers have successfully prepared B$\mathrm{N}$ doped carbon nanotubes [40-42]. With the ab initio molecular dynamics method, Yi et al. reported that the substitution of $\mathrm{B}$ and $\mathrm{N}$ has a great influence on the electronic properties of carbon nanotubes [43]. Shao et. al.have reported First-principles investigation on B/N co-doping of ultra small diameter metallic single-walled carbon nanotubes [38,39]. The present work aims at harvesting the idea of exploring the combinations of next neighbours as the dopants and uses the novel molecular designing as a tool for tuning the dielectric functions and refractive indices of SWCNTs. A pristine $(8,0)$ SWCNT, an $(8,0)$ SWCNT co-doped with Al and P, an $(8,0)$ SWCNT co-doped with Al, N \& P , a $(9,0)$ SWCNT doped with two Al atoms and a $(9,0)$ SWCNT co-doped with Al and B were modeled using the software material studio (version 7.0) and dielectric function spectra for each of the simulated structure were calculated using ab initio for polarized light, unpolarized light and light through polycrystalline media. The analysis of the dielectric function spectra obtained and static refractive indices thus calculated establishes co- 
doping as a novel and effective tool for manipulating these optical properties of SWCNTs. The study is of utmost importance as it will lead to the development of novel hybrid SWCNT systems with specific optical properties suitable for specific optical devices for various technological applications.

\section{Computational details}

In this theoretical work, all the calculations are implemented using Cambridge Sequential Total Energy Package (CASTEP) based on density functional theory [44]. CASTEP is available as a userfriendly module with the material studio software [45]. We performed the geometry optimizations and band structure calculations on a pristine $(8,0)$ zigzag type SWCNT, an Al-P co-doped SWCNT and an AL-N-P co-doped SWCNT. Like any ab initio calculation, the selfconsistent Kohn Sham (KS) equation has been used to compute the eigen functions here. For the exchange and correlation terms, we used the generalized gradient approximation (GGA) functional with the Revised Perdew-Burke-Ernzerhof (RPBE) sub-functional [46]. The choice of the functional sub-functional combination is based on the optimization of the parameters in a previous study which was done on a $(9,0)$ SWCNT [47]. The norm-conserving pseudo-potential in reciprocal space was selected for the optical properties calculations. The electronic wavefunctions were expanded in plane wave basis set with finite basis set correction. A cutoff energy of $500 \mathrm{eV}$ for the grid integration was used for computing the charge density. 3D triclinic super-cells were generated for BZ calculations (Fig.1).

The Brillouin zone integration was performed using the monkhorst-pack scheme. Self-consistent field (SCF) calculations were conducted using the convergence criteria detailed in the Table- 2 . Optical properties calculations were performed on the simulated structures of the pristine $(8,0)$ 
SWCNT, Al-P co-doped $(8,0)$ SWCNT and Al-N-P co-doped SWCNT to determine the dielectric function spectra. The results obtained were analyzed to deduce the affect of co-doping on the dielectric functions and refractive indices of the SWCNTs.

\section{Results and discussions}

\subsection{Exchange correlation optimization}

Band gap study was performed on a $(9,0)$ SWCNT during a previous work by the authors to determine which exchange correlation functional is the most suitable for DFT studies on a SWCNT [47]. The results obtained are tabulated in Table-1.

Comparing these results with the measurements made by Leiber et al. $\left(\mathrm{E}_{\mathrm{g}}=0.080 \mathrm{eV}\right)$ [48], it can be seen that GGA-RPBE / GGA-WC exchange correlation approximation is the most effective theoretical tool for DFT studies on SWCNTs. That is why; GGA functional in combination with RPBE sub-functional has been used for the DFT calculations in the current study.

\subsection{Geometry optimization}

Geometries of the pristine $(8,0)$ SWCNT, Al-P co-doped $(8,0)$ SWCNT and Al-N-P co-doped SWCNT structures were optimized w.r.t. energy change, maximum displacement, maximum force and maximum stress. Norm-conserving pseudo-potential was used in the reciprocal lattice with fixed basis set quality using gaussian smearing scheme without any periodic dipole correction. Plane wave basis set cut-off value was chosen to be $500 \mathrm{eV}$. The tolerance parameters specified for geometry optimization of pristine and co-doped SWCNTs are enlisted in Table- 2 . Successfully optimized geometries confirm the stability of the proposed nanomaterials to be developed by simultaneously doping the SWCNTs with different combinations of Al, N and P in 
different proportions. For the pristine SWCNT, the simulated structure converged in 17 iterations to a total energy of -146.1 eV. For Al-P co-doped SWCNT, pseudo atomic calculation performed for $\mathrm{C}\left(2 \mathrm{~s}^{2} 2 \mathrm{p}^{2}\right)$ converged in 17 iterations to a total energy of $-146.1 \mathrm{eV}$, for $\mathrm{Al}\left(3 \mathrm{~s}^{2} 3 \mathrm{p}^{1}\right)$, the calculations converged in 12 iterations to a total energy of $-53.8 \mathrm{eV}$ and for $\mathrm{P}\left(3 \mathrm{~s}^{2} 3 \mathrm{p}^{3}\right)$, the calculations converged in 17 iterations to a total energy of $-174.2 \mathrm{eV}$. For Al-N-P co-doped SWCNT, pseudo atomic calculation performed for $\mathrm{C}\left(2 \mathrm{~s}^{2} 2 \mathrm{p}^{2}\right)$ converged in 17 iterations to a total energy of $-145.6 \mathrm{eV}$, for $\mathrm{N}$, the calculations $\left(2 \mathrm{~s}^{2} 2 \mathrm{p}^{3}\right)$ converged in 21 iterations to a total energy of $-261.2 \mathrm{eV}$, for $\mathrm{Al}\left(3 \mathrm{~s}^{2} 3 \mathrm{p}^{1}\right)$, the calculations converged in 15 iterations to a total energy of $-53.6 \mathrm{eV}$ and for $\mathrm{P}\left(3 \mathrm{~s}^{2} 3 \mathrm{p}^{3}\right)$, the calculations converged in 17 iterations to a total energy of $-173.8 \mathrm{eV}$. DFT calculations resulted into an optimized cell volume of $525.11\left(\mathrm{~A}^{0}\right)^{3}$ for the pristine SWCNT, $1233.59\left(\mathrm{~A}^{0}\right)^{3}$ for Al-P co-doped SWCNT and $1819.40\left(\mathrm{~A}^{0}\right)^{3}$ for Al-N-P co-doped SWCNT.

\subsection{Dielectric function spectra and refractive-index calculation}

DFT calculations were set up for optical properties using CASTEP module of the software. For the pristine SWCNT, 2x2x3 monkhorst-pack grid was used for SCF calculation using 4 k points for Brillouin zone sampling; for Al-P co-doped SWCNT, 1x1x6 Monkhorst-Pack grid was used for SCF calculation using $3 \mathrm{k}$ points for Brillouin zone sampling while for Al-N-P co-doped SWCNT also, 1x1x6 Monkhorst-Pack grid was used for SCF calculation using $3 \mathrm{k}$ points for Brillouin zone sampling. In case of the pristine SWCNT as well as Al-P co-doped SWCNT, 76 energy bands were calculated and analyzed to deduce the dielectric function spectra with a band convergence tolerance value of $0.1 \times 10^{-4} \mathrm{eV}$ while in case of Al-N-P co-doped SWCNT, an additional band was observed in the band structure generated using the same band convergence value. The dielectric constant spectra were separately calculated for the unpolarized light, light 
polarized along z-axis and light through polycrystalline media. Fig. 2, 3 and 4 show the dielectric spectra in polarized light, unpolarized light and light through polycrystalline media for a pristine SWCNT, Al-P co-doped SWCNT and Al-N-P co-doped SWCNT respectively. The dielectric function of a material $(\varepsilon(\omega))$, characterize the electrical and optical properties versus wavelength, frequency or energy .The dielectric function can be defined by the following equation:

$$
\varepsilon(\omega)=\varepsilon_{1}(\omega)+\mathrm{i} \varepsilon_{2}(\omega)
$$

where $\omega, \varepsilon_{1}(\omega)$ and $\varepsilon_{2}(\omega)$ are incoming light frequency, real part and imaginary part of dielectric function respectively. The imaginary and real part of the dielectric function can be calculated by the following equations:

$$
\begin{gathered}
\varepsilon_{1}(\omega)=\delta_{\alpha \beta}+2 \mathrm{P} / \pi\left[0 \int^{\infty}\left\{\omega^{\prime} \varepsilon_{2}\left(\omega^{\prime}\right) / \omega^{\prime 2}-\omega^{2}\right\} \mathrm{d} \omega^{\prime}\right] \\
\& \\
\varepsilon_{2}(\omega)=\mathrm{h}^{2} \mathrm{e}^{2} / \pi \mathrm{m}^{2} \omega^{2} \sum \int \mathrm{dk} \mathrm{c}_{\mathrm{k}}\left|\mathrm{p}^{\alpha}\right| v_{\mathrm{k}} \nu_{\mathrm{k}}\left|\mathrm{p}^{\beta}\right| \mathrm{ck} \times \delta\left(\varepsilon_{\mathrm{ck}}-\varepsilon_{v \mathrm{k}}-\omega\right)
\end{gathered}
$$

where $\mathrm{m}$ is the electronic mass, e is magnitude of electronic charge and the subscripts $\alpha$ and $\beta$ are directional components. The static values of the dielectric function derived from these spectra have been tabulated in Table-3. Substantial difference in the values for polarized and unpolarized light indicates that the dielectric functions of pristine, Al-P co-doped as well as Al-N-P co-doped SWCNTs are anisotropic in nature. This anisotropicity is the most pronounced in the case of AlP co-doped SWCNT. Also, it can be observed that the presence of polycrystalline media also affects the values of dielectric function remarkably.

The static optical refractive index equals to the square root of the real part of the dielectric 
function at zero frequency:

$$
\mathrm{n}_{0}(\omega)=\sqrt{ } \varepsilon_{1}(0)
$$

where $\varepsilon_{1}(0)$ is the real part of dielectric function at zero frequency. The calculated optical refractive indices of the pristine and co-doped SWCNTs in polarized light, unpolarized light and the light through the polycrystalline media are tabulated in the Table- 4 . It can be seen that the refractive indices record a sharp increase by co-doping an $\mathrm{Al}$ and a $\mathrm{P}$ atom in the lattice structure of the Pristine SWCNT in unpolarized light as well as the light through polycrystalline media while in the polarized light a decrease in the value of the refractive index is observed. This shows that the co-doping of $\mathrm{Al}$ and $\mathrm{P}$ in the SWCNT structure enhances the anisotropicity of the optical properties. However, if an additional atom of $\mathrm{N}$ is co-doped alongwith $\mathrm{Al}$ and $\mathrm{P}$, refractive index is observed to decrease in polarized light, unpolarized light as well as light through polycrystalline media. Thus, it can be inferred that introduction of a foreign atom into the structure of a pristine SWCNT may increase or decrease the value of the refractive index depending on the nature and interactions of the atoms introduced. The performance of many solid-state devices including emissive displays, optical sensors, integrated optical circuits, and light-emitting diodes can be improved by applying a transparent high refractive index coating onto the light-emitting or light-sensing portion of the device. Through careful molecular designing, we can develop novel materials with desired values of refractive indices. Various figures of merit of different optical devices and instruments like Fresnel reflectance of interface, Distributed Bragg reflectance, Spectral width of stop band, Penetration depth and critical angle etc. are all dependent on the refractive indices of the component materials or coatings. Hence, a variety of novel optical materials need to be developed with a wide range of values of dielectric fn./refractive indices .Through this study, we suggest tha co-doping can be developed as an 
effective tool for tuning the dielectric function and refractive indices of the SWCNTs as per the specific requirements of various technological applications in optical devices.

\section{Conclusions}

Dielectric function spectra of pristine SWCNT, Al-P co-doped SWCNT and Al-N-P co-doped SWCNT have been studied and static refractive indices have been calculated thereafter. DFT calculations for these optical properties have been performed for polarized light, unpolarized light and the light through polycrystalline media. The results for polarized and unpolarized light are quite different reflecting anisotropicity of the studied optical properties, the degree of anisotropicity being the highest for Al-P co-doped SWCNT. Change in the values of these optical parameters speaks of the effect of the polycrystalline media on the optical phenomena involved. Increase in the value of dielectric function and refractive index on Al-P co-doping and decrease in these values on Al-N-P co-doping directly indicates the possibility of manipulating these optical properties by suitably co-doping different combinations of atoms into the pristine structures of SWCNTs. Co-doping thus presents itself as a novel and effective tool for tuning the optical properties of SWCNTs for application specific requirements.

\section{Acknowledgment}

Author Deepa Sharma would like to acknowledge the support of University Grants Commission of India as UGC faculty fellowship award. 


\section{REFERENCES}

1. M. Dresselhaus, G. Dresselhaus, Ph. Avouris (Eds.), Carbon Nanotubes: Synthesis, Structure, Properties, and Applications, Springer-Verlag, Berlin, 2001.

2. R.H. Baughman, A.A. Zakhidov, W.A. DeHeer, Science 297 (2002) 787.

3. D. Sharma \& N.Jaggi, Journal of Superconductivity and Novel Magnetism 30 (2017) 371.

4. Ph. Avouris, M. Freitag, V. Perebeinos, Nat. Photon. 2 (2008) 341.

5. N.M. Gabor, Z. Zhong, K. Bosnick, J. Park, P.L. McEuen, Science 325 (2009) 1367.

6. T. Hertel, Nat. Photon. 4 (2010) 77.

7. T. Mueller, M. Kinoshita, M. Steiner, V. Perebeinos, A.A. Bol, D.B. Farmer, Ph. Avouris, Nat. Nanotechnol. 5 (2010) 27.

8. E. Malic, C. Weber, M. Richter, V. Atalla, T. Klamroth, P. Saalfrank, S. Reich, A. Knorr, Phys. Rev. Lett. 106 (2011) 097401.

9. I.V. Bondarev, Phys. Rev. B 85 (2012) 035448.

10. F. Vietmeyer, B. Seger, P.V. Kamat, Adv. Mater. 19 (2007) 2935.

11. X. Dang, H. Yi, M.-H. Ham, J. Qi, D.S. Yun, R. Ladewski, M.S. Strano, P.T. Hammond, A.M. Belcher, Nat. Nanotechnol. 6 (2011) 377.

12. S. Nanot, E.H. Haroz, J.-H. Kim, R.H. Hauge, J. Kono, Adv. Mater. 24 (2012) 4977.

13. M.S. Dresselhaus, G. Dresselhaus, R. Saito, A. Jorio, Annu. Rev. Phys. Chem. 58 (2007) 719.

14. Editorial/ Chemical Physics 413 (2013) 1

15. A. Hagen, M. Steiner, M.B. Raschke, C. Lienau, T. Hertel, H. Qian, A.J. Meixner, A. Hartschuh, Phys. Rev. Lett. 95 (2005) 197401.

16. S. Piscanec, M. Lazzeri, J. Robertson, A. Ferrari, F. Mauri, Phys. Rev. B 75 (2007) 035427.

17. T.G. Pedersen, K. Pedersen, H.D. Cornean, P. Duclos, Nano Lett. 5 (2005) 291.

18. I.V. Bondarev, Phys. Rev. B 83 (2011) 153409.

19. I.V. Bondarev, L.M. Woods, K. Tatur, Phys. Rev. B 80 (2009) 085407. 
20. A. Srivastava, H. Htoon, V.I. Klimov, J. Kono, Phys. Rev. Lett. 101 (2008) 087402.

21. V. Perebeinos, Ph. Avouris, Nano Lett. 7 (2007) 609.

22. S. Barazzouk, S.Hotchandani, K. Vinodgopal, P.V. Kamat, J Phys Chem Mater 108(44) (2004) 17015.

23. M. Zhang, K.R. Atkinson, R.H. Baughman, Science 306 (2004) 1358.

24. A. Kongkanand, R.M. Dominguez, P.V. Kamat, NanoLett 7(3) (2007) 676.

25. S.C. Hou, X. Cai,Y.P. Fu, Z.B. Lv,D. Wang, H.W. Wu et al. , J Mater Chem Mater 21(36) (2011) 13776.

26. T. Chen, L.B. Qiu, Z.B. Cai,F. Gong,Z.B. Yang, Z.S.Wang et. al., Nano Lett. 12(5) (2012) 2568.

27. M.J. Uddin, T. Dickens, J.Yan, R. Chirayath, D.O. Olawale, O.I. Okoli, Sol Energy Mater Sol Cells $108(2013) 65$.

28. H. Rezania , Optik 126 (2015) 1918.

29. T.Sun, L. Feng, X.Gao, L. Jiang, Acc Chem Res 38 (2005) 644.

30. Y. Li, J. Zang, B. Yang, NanoToday 5 (2010) 117.

31. A. Högele, Ch. Galland,M.Winger, A. Imamoglu, Phys. Rev. Lett. 100 (2008) 217401.

32. I.V. Bondarev, J. Electron. Mater. 36 (2007) 1579.

33. O. Stephan, P.M. Ajayan, C. Colliex, P. Redlich, J.M. Lambet, P. Bernier, P. Lefin,Science 266 (1994) 1683;Z. Weng-Siehetal, Phys. Rev. B 51 (1995) 11229

34. M. Terrones, et al., Chem. Phys. Lett. 257 (1996) 576

35. J. Yu, et al., Appl. Phys. Lett. 77 (1998) 1949.

36. D. Sharma \& N.Jaggi, Optik-International Journal for Light and Electron Optics 131 (2017) 267.

37. X. Li, J. Shi, T. Zhao, R. Wan, C. Leng \& Y. Lei, Physica B: Condensed Matter 490 (2016) 63.

38. J. Xia, C.Shao, T. Wang, J. Zhang \& Q. Shao, Chemical Physics Letters 579 (2013 ) 127.

39. C.Shao, J. Xia, J. Zhang, J. \& Q.Shao, Physica E: Low-Dimensional Systems and Nanostructures 59 (2014) 88. 
40. D.Golberg, Y.Bando, W.Han et al., Chem. Phys. Lett. 308(3) (1999)337.

41. W.Han, Y.Bando, K.Kurashima et al. ,Chem.Phys.Lett. 299(5) (1999) 368.

42. M. Terrones, P.M.Ajayan, F.Banhart et al., Appl.Phys.A 74(3) (2002) 355.

43. J.Y. Yi, J. Bernholc, Phys. Rev. B 47 (3) (1993) 1708.

44. M. D. Segall et al., Journal of Physics: Condensed Matter 14 (2002) 2717.

45. Materials Studio. User's manual, version 7.0, Accelrys Inc., San Diego, CA

46. J. P. Perdew, Phys. Rev. Lett. 77 (1996) 3865.

47. D.Sharma, \& N. Jaggi, Canadian Journal of Physics 94(10) (2016) 1112.

48. Y Matsuda, J Tahir-Kheli \& W A Goddard III The Journal of Physical Chemistry Letters 12946 (2010) 
Fig. 1

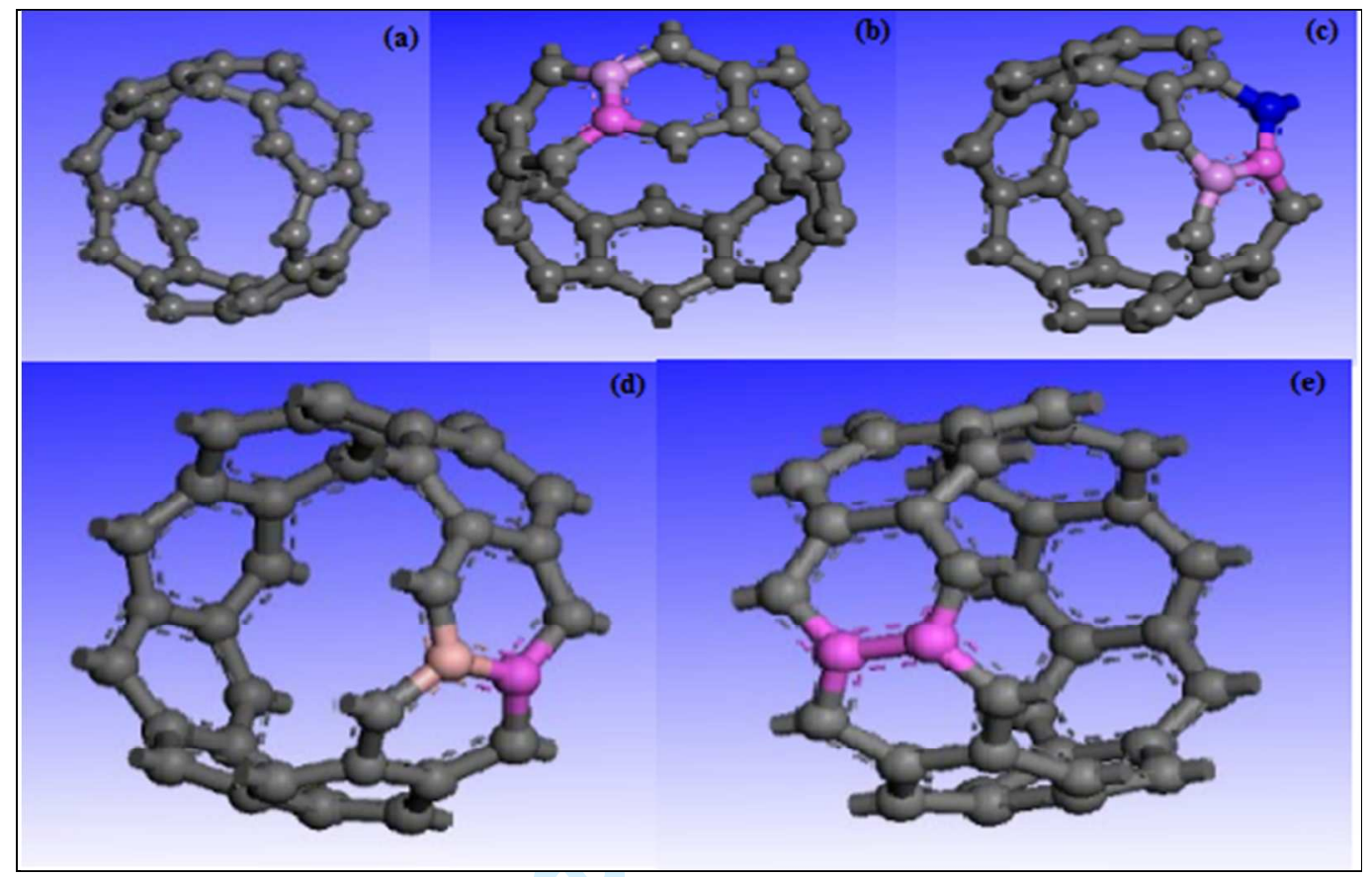

Fig. 1 simulated structure of a) pristine SWCNT; b) Al-P co-doped $(8,0)$ SWCNT; c) Al-N-P co-doped $(8,0)$ SWCNT; d) Al-B co-doped $(9,0)$ SWCNT; e) Al doped $(9,0)$ SWCNT

Fig. 2

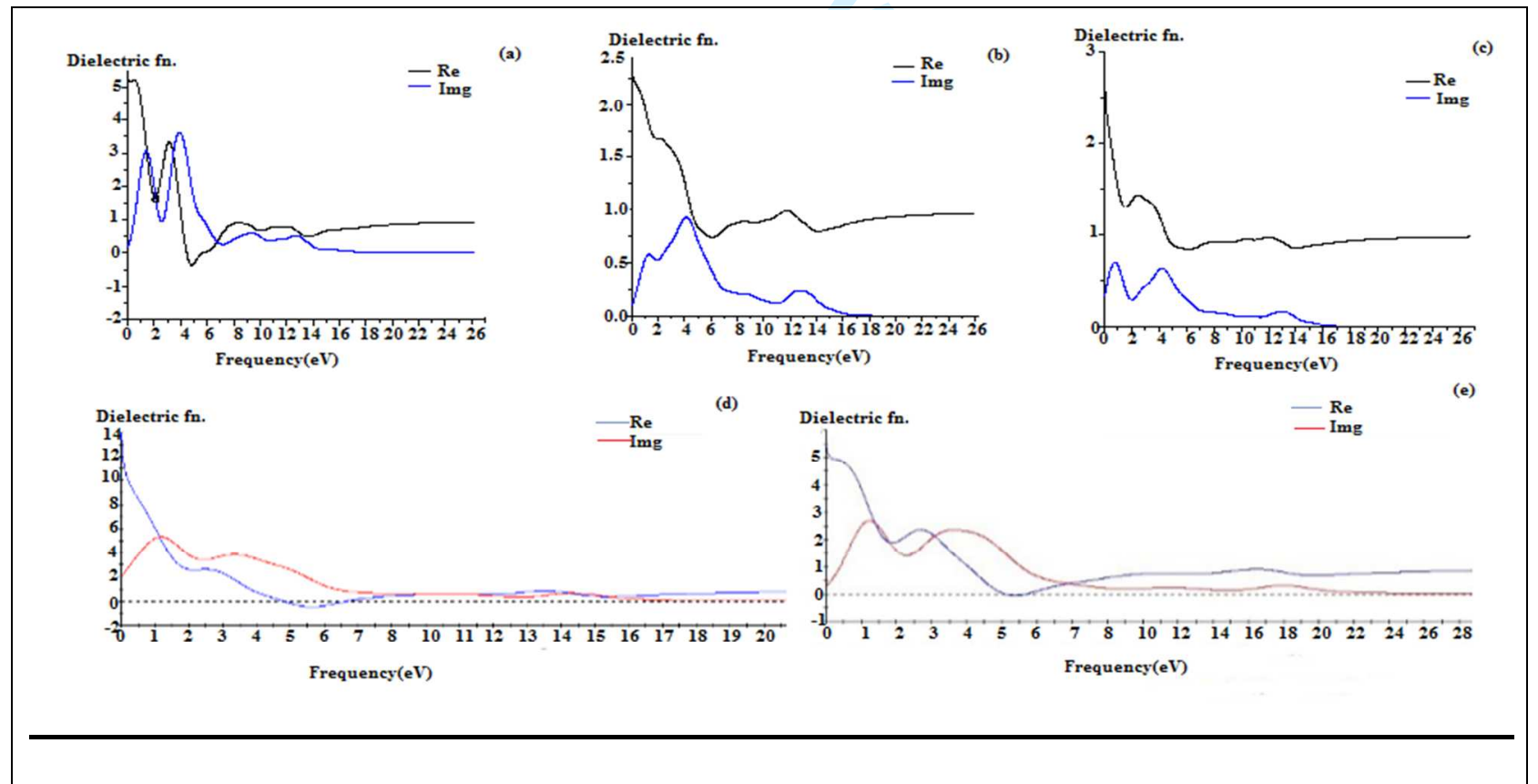

Fig.2 Dielectric function spectra of a) pristine $(8,0)$ SWCNT b) Al-P co-doped $(8,0)$ SWCNT c) Al-N-P co-doped $(8,0)$ SWCNT d) Al-B co-doped $(9,0)$ SWCNT and e) Al doped $(9,0)$ SWCNT in polarized incident light 


\section{Fig. 3}

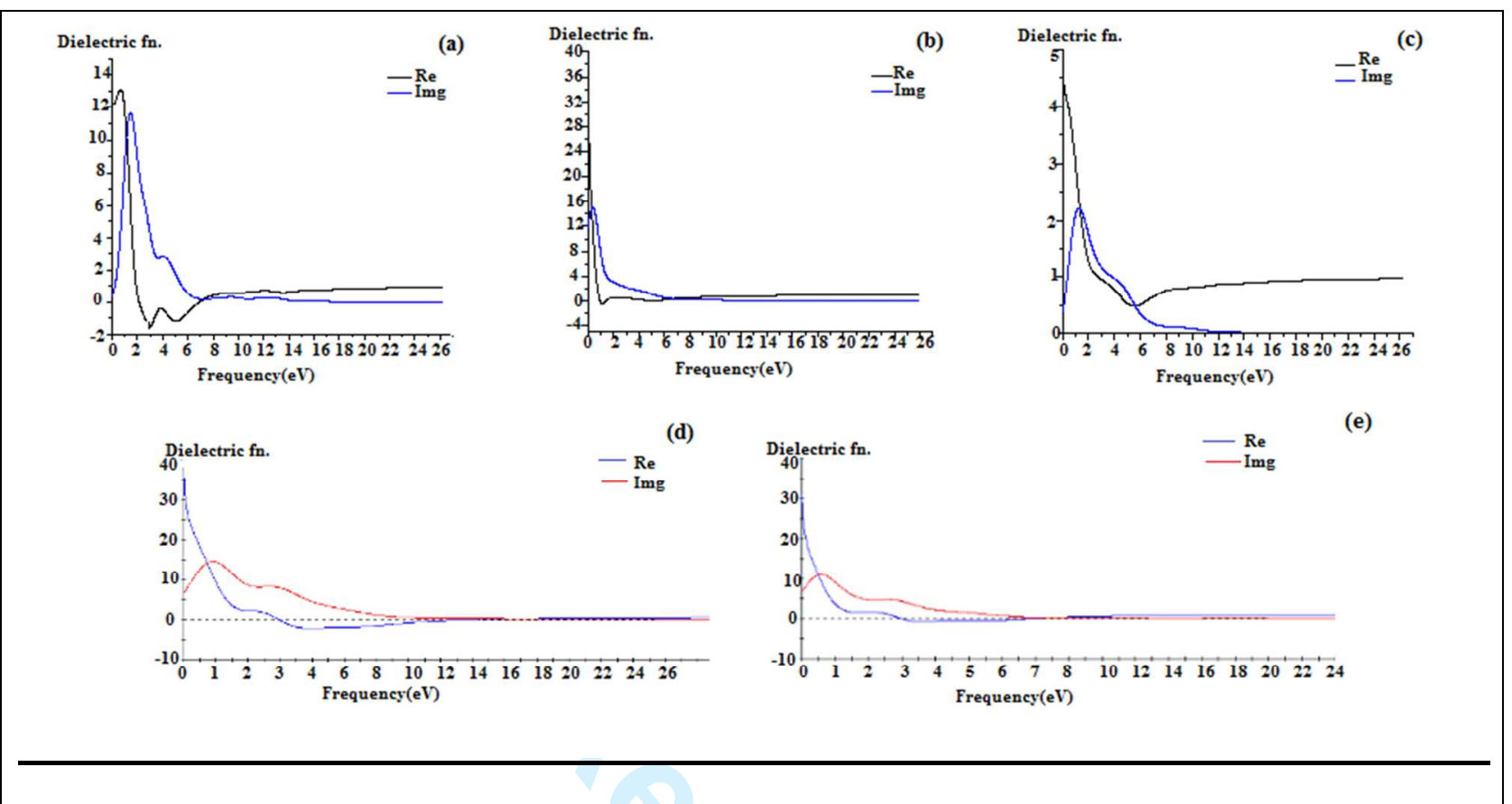

Fig.3 Dielectric function spectra of a) pristine $(8,0)$ SWCNT b) Al-P co-doped $(8,0)$ SWCNT c) Al-N-P co-doped $(8,0)$ SWCNT d) Al-B co-doped $(9,0)$ SWCNT and e) Al doped $(9,0)$ SWCNT in unpolarized incident light

\section{Fig. 4}

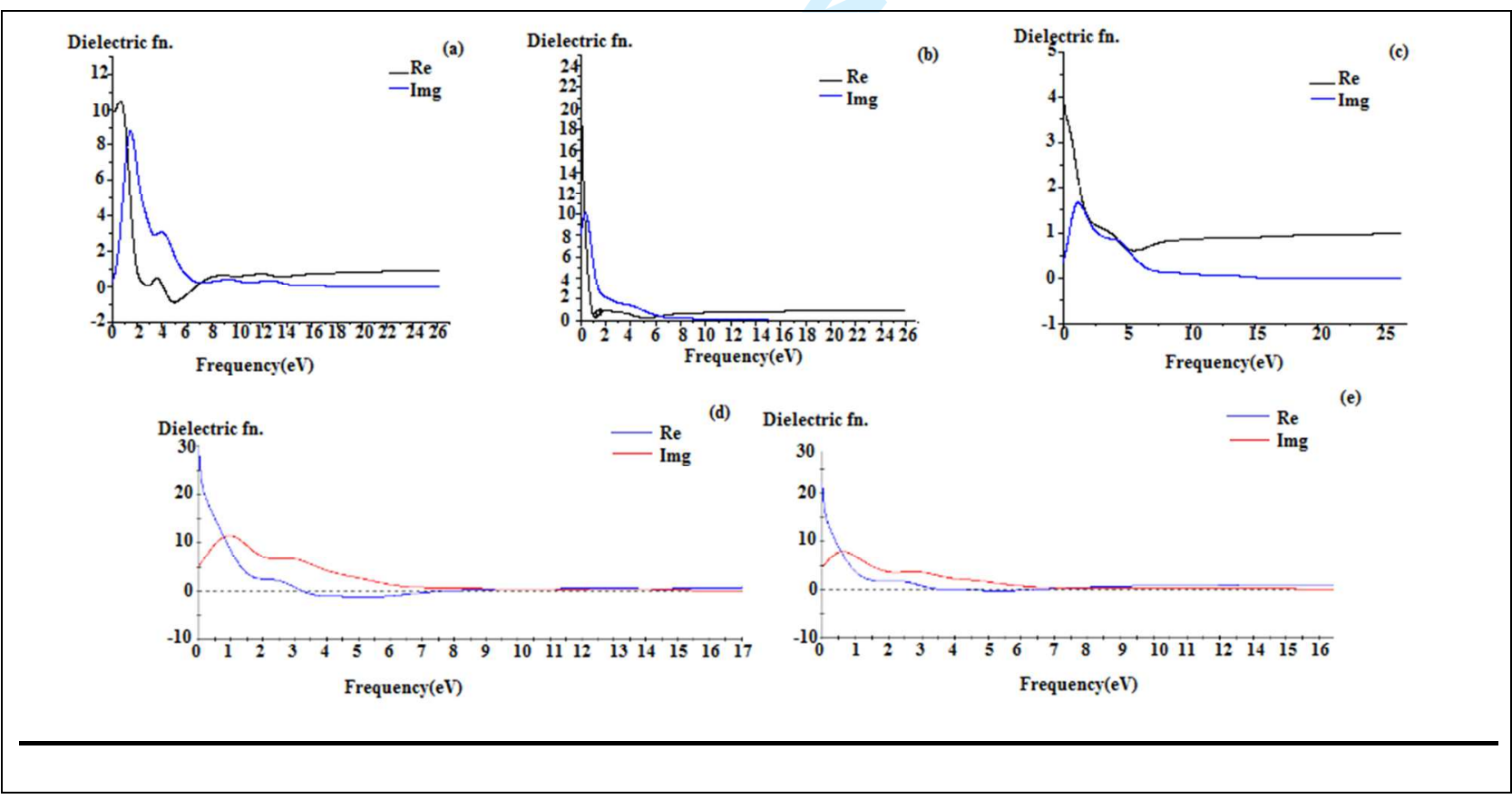

Fig.4 Dielectric function spectra of a) pristine $(8,0)$ SWCNT b) Al-P co-doped $(8,0)$ SWCNT c) Al-N-P co-doped $(8,0)$ SWCNT d) Al-B co-doped $(9,0)$ SWCNT and e) Al doped $(9,0)$ SWCNT in light incident through a polycrystalline medium 


\section{Table-1}

\begin{tabular}{|c|c|c|c|c|}
\hline \multicolumn{5}{|c|}{ EXCHANGE CORRELATION OPTIMIZATION } \\
\hline LDA & PBESOL & WC & PW91 \\
\hline CA-PZ & RPBE & $0.161 \mathrm{Ev}$ & $\mathbf{0 . 0 6 3 e V}$ & $0.003 \mathrm{Ev}$ \\
\hline $0.190 \mathrm{eV}$ & $\mathbf{0 . 0 9 7 e V}$ & & & \\
\hline
\end{tabular}

\section{$\underline{\text { Table-2 }}$}

\begin{tabular}{|l|l|l|l|l|}
\hline \multicolumn{5}{|c|}{ TOLERANCE CRITERIA FOR SYSTEM CONVERGENCE } \\
\hline & Total energy convergence & Max. force & Max. displacement & Max. stress \\
\hline Pristine & $0.2 \times 10^{-2} \mathrm{eV} /$ atom & $0.5 \times 10^{-1} \mathrm{eV} / \mathrm{A}^{0}$ & $0.2 \times 10^{-2} \mathrm{~A}^{0}$ & $0.1 \mathrm{GPa}$ \\
\hline Al-P co-doped & $0.2 \times 10^{-4} \mathrm{eV} /$ atom & $0.5 \times 10^{-1} \mathrm{eV} / \mathrm{A}^{0}$ & $0.2 \times 10^{-2} \mathrm{~A}^{0}$ & $0.1 \mathrm{GPa}$ \\
\hline Al-N-P co- & $0.2 \times 10^{-4} \mathrm{eV} /$ atom & $0.5 \times 10^{-1} \mathrm{eV} / \mathrm{A}^{0}$ & $0.2 \times 10^{-2} \mathrm{~A}^{0}$ & $0.1 \mathrm{GPa}$ \\
doped & & & & \\
\hline
\end{tabular}


$\underline{\text { Table-3 }}$

\begin{tabular}{|l|l|l|l|l|l|}
\hline \multicolumn{7}{|c|}{ STATIC DIELECTRIC FUNCTION } \\
\hline & Pristine $(8,0)$ & $\begin{array}{l}\text { Al-P co-doped } \\
(8,0)\end{array}$ & $\begin{array}{l}\text { Al-N-P co-doped } \\
(8,0)\end{array}$ & $\begin{array}{l}\text { Al-B co-doped } \\
(9,0)\end{array}$ & $\begin{array}{l}\text { Al doped } \\
(9,0)\end{array}$ \\
\hline Polarized & 5.4 & 2.4 & 2.9 & 10.9 & 6.1 \\
\hline Unpolarized & 12.6 & 36.2 & 4.9 & 35.9 & 25.4 \\
\hline Polycrystalline & 10.3 & & & 24.1 & 19.9 \\
\hline
\end{tabular}

\section{$\underline{\text { Table-4 }}$}

\section{STATIC REFRACTIVE INDEX}

\begin{tabular}{|l|l|l|l|l|l|}
\hline & Pristine (8,0) & $\begin{array}{l}\text { Al-P co-doped } \\
(8,0)\end{array}$ & $\begin{array}{l}\text { Al-N-P co-doped } \\
(8,0)\end{array}$ & $\begin{array}{l}\text { Al-B co-doped } \\
(9,0)\end{array}$ & $\begin{array}{l}\text { Al doped } \\
(9,0)\end{array}$ \\
\hline Polarized & 2.3 & 1.5 & 1.7 & 3.3 & 2.5 \\
\hline Unpolarized & 3.5 & 6.0 & 2.2 & 6.0 & 5.0 \\
\hline Polycrystalline & 3.2 & 4.6 & 2.1 & 4.9 & 4.5 \\
\hline
\end{tabular}

